\title{
El problema de la obligación política en Hobbes y Spinoza
}

\author{
LUIS SALAZAR \\ Departamento de Filosofía de la División de Ciencias Sociales y Humanidades \\ Universidad Autónoma Metropolitana-Iztapalapa \\ lsalazarc49@hotmail.com
}

\begin{abstract}
RESUMEN: En la primera parte de este ensayo se examinan algunas de las dificultades que suscita la teoría de la obligación política de Hobbes. Partiendo de la distinción propuesta por Rousseau entre poder de hecho y poder de derecho, se considera la forma en que el filósofo inglés intentó identificar las "leyes de la naturaleza" como teoremas racionales capaces precisamente de otorgar legitimidad racional al pacto fundacional del poder soberano, haciendo coincidir así lo racional con lo justo. A continuación se analizan los argumentos hobbesianos que pretenden refutar la "teoría del necio", esto es, de aquel que no acepta tal coincidencia, con el objeto de mostrar las debilidades "utópicas" de esos argumentos. En la segunda parte se muestra cómo Spinoza, partiendo aparentemente de premisas muy similares a las de Hobbes, en los hechos reformula radicalmente la perspectiva para proponer una concepción "realista", aunque democrática, de los procesos políticos de legitimación.
\end{abstract}

PALABRAS CLAVE: obligación política, legitimidad, racionalidad, poder

Criticando la idea del derecho del más fuerte (o de la ley del más fuerte), Rousseau apunta lo siguiente:

El más fuerte nunca es bastante fuerte para ser siempre el amo si no transforma su fuerza en derecho y la obediencia en deber. [...] La fuerza es un poder físico; no veo qué moralidad puede resultar de sus efectos. Ceder a la fuerza es un acto de necesidad, no de voluntad; es todo lo más un acto de prudencia. ¿En qué sentido podrá ser un deber? [...] Si hay que obedecer por fuerza, no hay que obedecer por deber, y si uno ya no está forzado a obedecer, ya no está obligado a ello. Se ve, por tanto, que esta palabra de derecho nada añade a la fuerza; aquí no significa nada en absoluto. [...] Convengamos, pues, que la fuerza no hace derecho y que sólo se está obligado a obedecer a los poderes legítimos. (Rousseau 1977, pp. 175-176)

En estas pocas líneas, el filósofo ginebrino resume con precisión no sólo las razones que permiten refutar toda versión simplista del poder como algo reductible al uso de la fuerza y de la violencia físicas, sino también algunos de los presupuestos fundamentales de la problemática moderna de 
la legitimidad o de la legitimación del poder político. Para volverse estable, nos dice, el poder sustentado en la fuerza debe transformarse en poder sustentado en el derecho convirtiendo la obediencia en deber. Ello implica una diferencia esencial entre ser forzado a realizar una determinada acción y tener la obligación (el deber) de realizarla. Una diferencia que abre una distancia infinita entre el poder de facto, el poder ilegítimo, que puede forzarnos pero no obligarnos a obedecer, y el poder de derecho, el poder legítimo al que tenemos la obligación de obedecer. La legitimidad, entonces, es un ingrediente irreductible a la fuerza y a la coacción, pues remite a la disposición subjetiva del agente, a su creencia de que, por las razones que sea, no sólo le conviene acatar los mandatos del titular del poder, sino que debe hacerlo porque cree que ese poder es un poder legítimo, esto es, que el que manda lo hace con derecho.

Pero ¿cómo se pasa de la fuerza al derecho, del poder coactivo al poder legítimo, de la fuerza pura a la fuerza legítima? ¿Qué permite esta extraña transformación que parece indispensable para dar estabilidad, permanencia y solidez al poder en la medida en que le otorga una vis directiva, una potencia espiritual capaz de alcanzar la conciencia moral de los individuos, y por ende le posibilita superar los motivos puramente estratégicos y circunstanciales de una obediencia interesada? Y todavía más, ¿se trata de una transformación racional, es decir, de un paso que puede justificarse racionalmente, o se trata, como sugería Étienne de la Boétie, de una malhadada costumbre, de un vicio promovido por los tiranos mediante una educación servil, así como mediante sobornos y corrupción? Éstos son algunos de los problemas que el iusnaturalismo moderno, inaugurado por Hobbes, pretende resolver racionalmente. No es casual que el tema de la obligación política en la obra del autor del Leviatán haya sido objeto de una abundante y compleja discusión entre los estudiosos anglosajones, a partir de la publicación del libro de Warrender, The Political Philosophy of Thomas Hobbes, ${ }^{1}$ dado que este tema condensa en efecto buena parte de las tensiones y posiciones que hacen de Hobbes un clásico insuperable del pensamiento político moderno.

En este horizonte parece pertinente intentar aclarar estas tensiones y posiciones hobbesianas relativas a la obligación política racional, contrastándolas con la manera en que Spinoza reformula la cuestión del pacto político y sus consecuencias para la legitimidad del poder así constituido. Con esta comparación, como veremos, podrán ponerse de manifiesto tanto las semejanzas y puntos de acuerdo entre estos dos autores, como

1 En relación con esta discusión, cfr. Taylor 1938, Nagel 1959, Warrender 1962a y 1962b, y Barry 1968. 
la sugerente distancia teórica que los separa y aun los opone filosófica y políticamente.

Que Hobbes tenía presentes las distinciones planteadas por Rousseau puede documentarse con el siguiente pasaje:

Y las bases de estos derechos [de mando del soberano] tienen más bien necesidad de ser diligente y verdaderamente enseñadas, porque no pueden ser mantenidos por ninguna ley civil o por el terror del castigo legal. Pues una ley civil que prohibiera la rebelión (y tal es toda resistencia a los derechos esenciales de la soberanía) no es (en cuanto ley civil) obligación alguna, sino por virtud solamente de la ley natural que prohíbe la violación de la fe; obligación natural que, si los hombres no la conocen, no pueden conocer el derecho de ninguna ley que el soberano haga. Y en lo que respecta al castigo, no lo toman sino como un acto de hostilidad, que, cuando piensen que tienen la fuerza suficiente, se esforzarán por rechazar mediante actos de hostilidad. (Hobbes 1994, p. 220)

La sola amenaza o uso de la fuerza aparece, así, según Hobbes, como hostilidad que puede y debe repelerse con la fuerza. Por ello se requiere la ley de naturaleza, ese dictamen de la razón o teorema que afirma nuestro "deber" de cumplir los pactos y, por ende, de respetar el pacto constitutivo del poder soberano, para aceptar plenamente los derechos de dicho poder y nuestra obligación natural de obediencia. A primera vista, entonces, tienen razón los que afirman que el iusnaturalismo hobbesiano supone, como cualquier otro iusnaturalismo, la precedencia y la prioridad de la moralidad (de una determinada concepción de la moralidad, al menos) como fundamento de la obligación política. No obstante, esta tesis, que encuentra sin duda apoyo en algunos textos del filósofo de Malmesbury, no es fácil de compatibilizar o de hacer consistente con otros textos, a más de plantear el espinoso problema del fundamento del fundamento, esto es, de las razones que según el propio Hobbes dan fuerza vinculante (moral/racional) a las propias leyes de naturaleza.

El estatuto de estas pretendidas "leyes", de las que Hobbes mismo señala que no debieran estrictamente denominarse así, pues una ley propiamente dicha es "la palabra de un hombre que por derecho tiene mando sobre otros" (Hobbes 1994, p. 100), es en verdad extraño. Aparecen como teoremas, como artículos de paz sugeridos por la razón y como preceptos o reglas generales "que prohíben (a un hombre) hacer aquello que es destructivo de su vida, u omitir aquello por lo que piensa que puede ser mejor preservada" (Hobbes 1994, p. 79). Pero si no son leyes sensu strictu, ¿son equiparables a consejos? Estos últimos son definidos en el Leviatán como "cuando un 
hombre dice haz o no hagas esto, y deduce sus razones del beneficio que llegará a aquel a quien se lo dice" (Hobbes 1994, p. 166). De donde derivan dos diferencias entre el consejo y el mandato: la primera se relaciona con el beneficiario supuesto del mismo; la segunda con la no obligatoriedad del consejo: "un hombre puede ser obligado a hacer lo que se le manda cuando ha pactado obedecer, pero no puede obligársele a hacer lo que se le aconseja, porque el daño de no hacerlo es sólo suyo; o si ha pactado seguirlo, entonces el consejo adquiere la naturaleza de un mandato" (Hobbes 1994, p. 166).

Ahora bien, ¿no se orientan las llamadas leyes naturales al beneficio de cada hombre, esto es, a la preservación de su vida? ¿No son, entonces, "consejos" que la razón nos sugiere, dado que el daño que se sigue de no obedecerlas es sólo nuestro? Hobbes no aclara el punto, quizá por suponer que siempre habría una gran diferencia entre los consejos particulares y circunstanciales que pueden darse o recibirse en un momento dado, y estos artículos o reglas generales deducidas racionalmente, y por ende válidas necesaria y eternamente en el foro interno. La fuerza vinculante de las leyes naturales sería mayor que la de cualquier consejo propiamente dicho, precisamente porque, al sustentarse en la razón, no dependería ni de los intereses ni de la inteligencia particulares del consejero, ni tampoco del peculiar contexto de su comunicación, sino de una demostración apodíctica que nos interpela como seres racionales, es decir, como agentes capaces de reconocer que el mal mayor es la muerte violenta y prematura, y que para evitarla es necesario, siempre y en todos los casos, buscar la paz (si hay esperanza de lograrla), abandonar nuestro derecho natural (si los demás están dispuestos a hacer lo propio), cumplir los pactos (si hay garantías de reciprocidad), ser agradecidos, etc., etc. En cambio, aceptar o no un consejo seguirá dependiendo simplemente de nuestra confianza en la inteligencia o sagacidad de aquel que nos lo proporciona.

Por lo tanto, Hobbes tendrá que demostrar que, para evitar la muerte violenta y conservar la vida, debemos estar dispuestos a acatar siempre, al menos en el foro interno, las leyes naturales y en particular la tercera, que nos ordena cumplir los pactos. En otras palabras, estamos obligados a querer respetarlas aun si, en una situación de guerra de todos contra todos, como la que existe cuando no hay un poder común, esta voluntad debe sujetarse a la segunda cláusula de la primera ley natural, a saber, "utilizar todas las ayudas y ventajas de la guerra" mientras no existan posibilidades de lograr la paz. Lo que implica, precisamente, suspender su vigencia en el foro externo; es decir, no respetarlas in foro externo en virtud de que no puede haber ninguna seguridad o garantía de que los demás las respetarán. Hasta aquí parece claro que la obligatoriedad racional de las leyes naturales se sustenta en 
un razonamiento estratégico, en un imperativo hipotético, que nos ordena buscar la paz, cumplir los pactos, ser agradecidos y equitativos, y, en suma, no hacer a otros lo que no queremos que nos hagan a nosotros, en tanto que ello nos permite evitar la muerte violenta y prematura. Nótese bien que tal razonamiento no parece requerir en ningún momento la figura de un Dios omnipotente para justificar la naturaleza obligatoria de estas leyes naturales. Sólo requiere que se acepte que la muerte prematura y dolorosa es el mal mayor y, por ende, aquello que, si somos racionales, debemos evitar a cualquier costo.

Es cierto que Hobbes apunta, después de reconocer que las leyes naturales no son propiamente leyes, sino teoremas o reglas racionales, que "si se consideran estos mismos teoremas como entregados en la palabra de Dios, que por derecho manda sobre todas las cosas, entonces son llamados propiamente leyes" (Hobbes 1994, p. 100). Ahora bien, la pregunta es si sólo entonces adquieren fuerza para obligar, como sostienen Taylor y Warrender, o si sólo entonces merecen el nombre de leyes. De hecho, lo segundo es lo único que se deriva de las afirmaciones de Hobbes y parece relacionarse exclusivamente con su obsesión de utilizar las palabras de acuerdo con definiciones precisas. Si las leyes son mandatos de una autoridad, si Auctoritas non veritas, facit legem, entonces las reglas o artículos de paz que la razón sugiere, y sobre los cuales los hombres "pueden ponerse de acuerdo", no deben denominarse leyes propiamente. Pero no por eso carecen de capacidad para obligarnos en cuanto que somos o seamos racionales.

Por lo demás, la idea de que esa capacidad deriva de su naturaleza de mandatos divinos nos llevaría a aceptar que, por alguna razón, Dios nos obliga "moralmente" a evitar la muerte violenta y prematura como el mal mayor, lo que difícilmente puede sostenerse en las tradiciones cristianas si consideramos que para ellas el mal mayor es el odio o el olvido de Dios. Nos llevaría a aceptar, en otros términos, que lo único que prohíbe Dios, que lo único que es pecado, es la estupidez, pues lo que nos exige en realidad no es amar al prójimo ni amarlo a Él, sino, con egoísmo absoluto y exclusivo, evitar la muerte violenta y prematura, algo así como que cada uno se ame a sí mismo por encima de cualquier otra consideración: extraño "mandamiento" divino. Lo que, por cierto, parece plenamente consistente con la afirmación hobbesiana de que nuestro deber de obediencia hacia Dios no se funda en que lo veamos como nuestro creador o nuestro padre, sino, también exclusivamente, en su poder irresistible, esto es, en el temor que puede infundirnos.

En suma, las leyes naturales no son leyes en sentido estricto, sino normas derivadas de la razón sobre lo que nos conduce a evitar la muerte violenta y prematura. Estas normas fundan entonces su obligatoriedad en el hecho 
de que nuestro conatus todo nos impulsa a conservar la vida (la circulación de la sangre, el movimiento vital interno) y, por ende, a evitar la muerte. Dado que la razón no es más que el cálculo de las consecuencias a partir del conocimiento de las causas, puede decirse que estas "leyes" no son otra cosa que el resultado de calcular las consecuencias de seguir (o no) determinadas reglas de acción. Si seguimos, por ejemplo, la regla que nos dice que debemos respetar los pactos, la razón nos dice que podremos lograr la paz, y por ello podremos evitar la muerte violenta y prematura. $\mathrm{Si}$, en cambio, desobedecemos esta norma, entonces no sólo no lograremos la paz, sino que además nos colocaremos en la peor situación dentro del estado de guerra, pues ni siquiera podremos tener aliados para defender en esa condición nuestra vida. De ahí que lo justo (cumplir los pactos) y lo racional (evitar la muerte) no sólo sean compatibles: son enteramente coincidentes para Hobbes.

Lo que explica su argumentación en contra del necio:

El necio ha dicho en su corazón "no hay tal cosa como la justicia"; y algunas veces también con su lengua, alegando seriamente que "si la conservación y el contento de cada hombre están a cargo de su propio cuidado, no habría ninguna razón para que cada hombre no pudiera hacer lo que piensa que es conducente para ello, y, por ende, también hacer o no hacer, respetar o no respetar los pactos no va contra la razón, cuando conduce al beneficio propio". (Hobbes 1994, p. 90)

En este pasaje Hobbes resume, por así decirlo, buena parte de las dificultades que desde siempre han agobiado a las tradiciones idealistas de la filosofía política. ¿Cómo mostrar que lo racional coincide con lo bueno o con lo justo? Ya Platón se había enfrentado a este problema, pero al menos él tenía la ventaja de partir de una clara separación entre el bien aparente (el del cuerpo y sus sentidos) y el bien verdadero (el del alma y su trascendencia). Para el egoísmo normativo hobbesiano, en cambio, el asunto parece mucho más difícil. Si lo bueno propiamente dicho coincide con la conservación de la vida, mientras que lo verdaderamente malo se identifica con la muerte prematura y violenta, entonces es necesario demostrar que lo justo, entendido como el cumplimiento de la fe, de la palabra dada, de lo pactado, coincide con los requerimientos de lo verdaderamente bueno así entendido y que lo injusto se identifica con lo malo racionalmente comprendido. Lo que, por decir lo menos, parece chocante a la luz de la evidencia empírica, y si el que ha de juzgar, en cada caso, es el individuo concreto en una situación concreta, pues está claro que aparentemente hay muchos ejemplos de que incumplir la palabra dada parece más benéfico que cumplirla, aun si suponemos que ese beneficio debe estar relacionado 
con la conservación de la vida y con la evitación de la muerte prematura y violenta.

No obstante, veamos con algún detenimiento los argumentos con que Hobbes pretende refutar esta postura del necio. Sin ser tan convincentes como el filósofo inglés parece suponer, al menos aclaran su posición sobre el carácter de las leyes naturales y sobre la naturaleza de la obligación política que de ellas se deriva.

Para empezar, señala que en un estado de guerra como el que existe en una situación prepolítica no se puede hablar con propiedad de pactos, por lo que el problema sólo sería si no va contra la razón cumplir lo prometido cuando a) la otra parte ya ha lo ha hecho, otorgando así algún beneficio, o cuando b) ya existe un poder capaz de asegurar el cumplimiento general de los pactos. En estos casos, afirma Hobbes:

Yo digo que no va contra la razón. Para probarlo debemos considerar: primero, que cuando un hombre hace algo que, hasta donde puede preverse o calcularse racionalmente, tiende a su propia destrucción, aunque ocurra algún accidente que él no puede prever y que convierta en benéfico este acto; sin embargo, tales eventualidades no lo hacen algo razonable o sabiamente hecho. En segundo lugar, que en una condición de guerra en la que todo hombre es enemigo de todo hombre, por falta de un poder común que los mantenga a todos a raya, no hay hombre que pueda esperar defenderse de la destrucción de sí mismo con sus propias fuerzas y su ingenio, sin la ayuda de aliados, cuando cada uno espera la misma defensa de la alianza que todos los demás. Y, por ende, aquel que declara que piensa que es racional engañar a los que lo han ayudado no puede esperar racionalmente ningún otro medio de seguridad que los que tiene en su propio poder individual. En consecuencia, quien quebranta su pacto y por ende declara lo que piensa que con razón puede hacer, no puede ser recibido en ninguna sociedad que una a los hombres para la paz y la defensa, sino por error de aquellos que lo reciben. Errores que no pueden considerarse razonablemente como medios para su seguridad; y, por consiguiente, si es abandonado o echado de la sociedad, perece. Y si vive en sociedad es por errores de los otros hombres, que no puede ni prever ni calcular. Consecuentemente (ha actuado) contra la razón de su preservación, e igual que como todos los hombres que no contribuyen a su destrucción y lo toleran sólo por ignorancia de lo que es bueno para ellos mismos. (Hobbes 1994, pp. 91-92)

Debe reconocerse que la cita anterior no deslumbra por su claridad. Pero, tratando de desentrañar sus secretos, es posible señalar que la objeción fundamental a los necios que oponen justicia y racionalidad consiste en señalar que el incumplimiento de los pactos no puede ser racional en la medida en que nos conduce, en el estado de naturaleza, a la mayor soledad y vulnerabilidad, por cuanto obstaculiza cualquier alianza estratégica, pues el que rompe sus pactos "declara" con ello mismo que nadie puede confiar 
racionalmente en él. Y que en el estado de sociedad civil sólo por error e ignorancia es posible que el que no cumple sus pactos (o cree que no es siempre racional hacerlo) no sea echado o considerado como un enemigo público. En un caso como en el otro, se tratará de una acción irracional, pues en cada uno de ellos el no imposible pero sí contingente éxito de la misma se deberá a un factor no calculable ni previsible, esto es, los errores y la ignorancia de los demás.

Es conveniente advertir, sin embargo, que Hobbes mismo parece darse cuenta de cierta fragilidad de sus argumentos al señalar que lo que quiere mostrar no es tanto que sea siempre racional cumplir las promesas (al menos si la contrapartida ya ha cumplido su palabra), sino que no va "contra la Razón" [against Reason]. Aun así, no deja de sorprender que Hobbes considere como algo absolutamente imprevisible e incalculable la posibilidad de que los demás se dejen engañar por error o por ignorancia. Después de todo, lo que parece demostrar no es que sea irracional incumplir las promesas y romper los pactos, sino que es irracional declarar, hacer pública, la disposición de hacerlo. En otras palabras, el irracional sería Maquiavelo (que por algo nunca fue maquiavélico), pero no César Borgia (que por poco se sale con la suya). Faltar a la palabra dada, cometer fraude y engañar a quienes han establecido un pacto con nosotros, por basarse en la ignorancia o tontería de los que han creído en esa palabra, es decir, por un factor no cabalmente calculable y previsible, supone, de acuerdo con Hobbes, actuar irracionalmente en la medida en que, si somos descubiertos, o bien perderemos la posibilidad de ser ayudados por otros en el estado de naturaleza, o bien seremos echados o penalizados en la sociedad civil. En consecuencia, "la justicia, esto es, el cumplimiento de los pactos, es una regla de la razón que nos prohíbe hacer cualquier cosa destructiva de nuestra vida y, por ende, una ley de naturaleza" (Hobbes 1994, p. 92).

Ahora bien, parece razonable apuntar que es imposible calcular y prever cabalmente la ignorancia o los errores de los demás, y que por lo tanto una acción fraudulenta siempre supone los riesgos que Hobbes indica. Pero es igualmente razonable pensar que también es imposible calcular y prever cabalmente que los demás actuarán siempre de acuerdo con esta regla y que, dejándose llevar por la ignorancia y el error, no intentarán a su vez actuar de mala fe. Claro está que por eso Hobbes descarta que los acuerdos en el estado de naturaleza puedan ser verdaderos pactos, pues no existe un poder común que los garantice penalizando el fraude. Pero ni siquiera la presencia de este poder parece bastar si no añadimos otros presupuestos: que todos estemos dispuestos a actuar de acuerdo con esa regla de la razón, esto es, que nadie apueste por la ignorancia y los errores de los demás, incluido, naturalmente, el o los titulares del poder soberano. De alguna manera, la 
racionalidad de la acción de cada individuo, esto es, la racionalidad del cumplimiento de los pactos, parece depender de que todos los otros individuos también reconozcan y respeten cabalmente la regla racional. Sólo si todos sabemos y reconocemos que es irracional incumplir lo pactado, por cuanto ello tiende a nuestra destrucción, sólo si todos actuamos en consecuencia, será realmente racional actuar con justicia. Pues si, por el contrario, lo que predomina es la irracionalidad, la ignorancia y el error, entonces, exista o no un poder soberano, será más bien contra la razón cumplir, al menos en algunos casos, los pactos.

A lo anterior, Hobbes quizá podría replicar que precisamente esta última situación implicaría que seguimos en un estado de naturaleza y, por ende, de guerra de todos contra todos, en el que es racional emplear todas las ventajas de la guerra, incluyendo el fraude y el engaño. Y que la función del poder soberano es justamente establecer las leyes positivas y los tribunales capaces de castigar el fraude generando así la confianza recíproca para que los pactos tengan vigencia efectiva. Y que además es función del poder soberano "enseñar diligentemente" la ley de naturaleza que prohíbe la violación de la fe. Pero lo primero parece suponer una especie de racionalidad y eficacia perfectas de los sistemas de justicia penal, pues sólo así esa garantía eliminaría la posibilidad de que los injustos se salieran con la suya, engañando a los encargados de impartir justicia, mientras que lo segundo parece implicar una desmedida fe en el poder de la enseñanza moral.

En realidad, lo que a Hobbes le interesa centralmente es demostrar que no sólo es siempre injusto rebelarse contra el poder constituido (por cuanto supone incumplir el pacto fundacional del mismo), sino que, además, es necesariamente irracional hacerlo, aun si por accidente (esto es, debido a la ignorancia y el error) esa rebelión tiene éxito. Por eso argumenta lo siguiente: "En lo que respecta a alcanzar la soberanía mediante la rebelión, es manifiesto que, aunque se consiga, dado que ello no puede esperarse (sino más bien lo contrario) y dado que al ganarse así se enseña a otros a ganarla de la misma manera, el intento es por ello contra la razón" (Hobbes 1994, p. 92).

Nada expresa mejor que este pasaje la distancia que separa la teoría hobbesiana de la práctica política real. Naturalmente, Hobbes era perfectamente consciente de esa distancia, al extremo de comparar su doctrina con la de Platón. No obstante, pensaba también, muy platónicamente, que era posible salvar dicha distancia mediante dos recursos: la constitución de un poder absoluto capaz de concentrar y unificar la fuerza de todos los súbditos bajo una voluntad única, y la enseñanza oficial de esa misma doctrina, capaz a su vez de volver enteramente racionales a esos mismos súbditos y 
también, obviamente, al titular (o a los titulares) del poder soberano. De ahí este curioso contrafáctico:

Aunque nada de lo que hacen los mortales puede ser inmortal, sin embargo, si los hombres tuvieran el uso de la razón que pretenden tener, sus Estados podrían asegurarse al menos de perecer por enfermedades internas. Porque por la naturaleza de su institución están diseñados para vivir tanto como la humanidad o como las leyes de naturaleza o como la justicia misma, que les da vida. Por lo tanto, si llegan a disolverse, no por violencia externa, sino por desorden intestino, la falta no está en los hombres en cuanto que son su materia, sino en cuanto que son hacedores y ordenadores de ellos. (Hobbes 1994, p. 210)

Si los hombres tuvieran el uso de la razón, entonces orientarían su conducta no ya por consideraciones y evaluaciones casuísticas, por cálculos y anticipaciones azarosas acerca de lo que les conviene, sino por las leyes de la naturaleza, esto es, por reglas generales fundadas en una racionalidad de pretensiones apodícticas. Sabrían entonces que, aunque una rebelión pueda tener éxito casualmente y aunque un fraude pueda ser benéfico ocasionalmente, sus deberes como agentes racionales serían cumplir lo pactado, obedecer al soberano y no defraudar a quienes han confiado en ellos.

En este sentido, el egoísmo que Hobbes atribuye a los hombres no se guía por la utilidad del acto individual, sino por la utilidad de seguir la regla general, ${ }^{2}$ lo cual permite entender el curioso ejemplo que Hobbes propone para justificar la validez de los pactos motivados por el miedo, el pacto que realizan los rehenes con sus secuestradores. $\mathrm{Al}$ respecto, argumenta nuestro autor que, dado que al ser liberado el rehén ha recibido un bien a cambio de una promesa, tiene la obligación de cumplirla a menos que el soberano (en una sociedad civil) lo descargue de tal obligación. Y la razón es que:

es un contrato en el que uno ha recibido el beneficio de la vida; y el otro ha de recibir dinero o un servicio por ello. Y, consecuentemente, cuando ninguna otra ley prohíbe su cumplimiento, el contrato es válido. Y aun en los Estados, si yo fuera forzado a liberarme de un ladrón prometiéndole dinero, estaría obligado [bound] a pagarle, a menos que una ley civil me exonerara de ello. Porque todo lo que puedo hacer legítimamente [lawfully] sin obligación, lo mismo puedo pactarlo legítimamente por miedo. Y lo que puedo pactar legítimamente no lo puedo quebrantar legítimamente. (Hobbes 1994, p. 86)

Parece evidente que, con este ejemplo, Hobbes intenta evitar que el miedo se transforme en una razón que invalide los pactos. Tal cosa destruiría la asimilación que realiza de la soberanía por institución y la soberanía por

2 Sobre este egoísmo normativo, cfr. Moore 1971 y 1972, así como Kavka 1986. 
conquista, dado que en esta última los súbditos pactan obediencia justamente para evitar perder la vida; pero también afectaría el pacto generador del soberano por institución, en virtud de que igualmente éste es motivado por miedo (aunque, en tal caso, el miedo horizontal propio del estado de guerra de todos contra todos). Ahora bien, ¿cómo pretende justificar Hobbes esta chocante idea de que debemos cumplir incluso los convenios hechos bajo amenaza de muerte? Decir, por ejemplo, que esta obligación es racional porque, de no ser respetada, podría tener como consecuencia que, si volvemos a caer en manos de secuestradores, éstos ya no tendrían razón alguna para confiar en nosotros, parece sustentar dicha racionalidad en mucha mala suerte, o bien, quizá más acertadamente, parece señalar que la racionalidad de las leyes de la naturaleza y, por ende, su fuerza "obligante" no tienen como base la situación específica de individuos particulares y sus beneficios concretos, sino el beneficio general de los seres humanos en situaciones también generales. Lo que refuerza la impresión de que los teoremas racionales que se identifican con las leyes u obligaciones morales sólo coinciden con la utilidad general de los seres humanos (con su convivencia pacífica), pero no necesariamente con su conveniencia particular en cada caso concreto.

De esta forma, el contrafáctico hobbesiano tendría que decir lo siguiente: si los hombres fueran racionales y siempre actuaran en función de reglas generales de convivencia (las leyes de la naturaleza), entonces la justicia y la utilidad de todos coincidirían. Pero tal proposición parece implicar como sustento normativo un principio de equidad que necesariamente va mucho más lejos que el mero hecho de la igualdad postulada por Hobbes. Un principio de equidad que también da fuerza propiamente prescriptiva a la regla de oro según la cual no debemos hacer a los demás lo que no queremos que se nos haga a nosotros mismos, y que supone, precisamente, que asumimos que nadie puede pretender superioridad para sí mismo ni inferioridad para los demás. Por supuesto, Hobbes mismo reconoce que las pasiones humanas se oponen radicalmente al cumplimiento espontáneo de las leyes de la naturaleza y por ello es justamente necesaria la existencia de un poder coactivo, de un soberano capaz de asegurar esa coincidencia de la justicia y la utilidad. Sólo apoyándose en la pasión más poderosa, en el miedo a la muerte violenta y prematura, será posible entonces lograr un respeto general de esos teoremas transformándolos en leyes positivas, en normas respaldadas por la coacción.

El círculo argumentativo parece cerrarse: las leyes de la naturaleza fundamentan la obligación racional de obedecer las leyes positivas, mientras éstas, sustentadas en la coacción, garantizan la posibilidad de que aquéllas valgan también in foro externo. Y el resultado es cancelar la brecha entre los 
dictados de la conciencia (moral) y las exigencias del poder político, evitando cualquier posibilidad de sedición basada en reclamos de justicia contra las leyes o las acciones del soberano. La moral normativa y laica, derivada de la razón, que Hobbes propone, parece resolverse así en un imperativo político capaz de superar incluso las acciones o leyes aparentemente "injustas" del soberano, pues sólo él puede fijar el significado preciso de lo que es justo, el significado, por ende, de aquellas leyes de la naturaleza. Toda rebelión, toda crítica, todo reclamo al poder establecido se revelan así simplemente como consecuencia de la ignorancia, del error y de las supersticiones de los hombres que, por carecer del método correcto y racional, se dejan llevar por sus pasiones antipolíticas. Si, además, el titular de la soberanía, que por definición no tiene obligación ninguna respecto de sus súbditos, logra guiarse por esas leyes de la naturaleza y por su propio egoísmo ilustrado, tendremos finalmente que los imperativos de la justicia y los imperativos de la razón coinciden enteramente.

Esta sorprendente utopía hobbesiana no deja, sin embargo, de plantear dudas, en especial por su relación con la práctica política real. El propio Hobbes reconocía explícitamente este problema al señalar:

Y ahora, considerando cuán diferente es esta doctrina de la práctica de la mayor parte del mundo, especialmente de sus partes occidentales, que han recibido su enseñanza moral de Roma y Atenas, y cuánta profundidad de filosofía moral se requiere en aquellos que tienen la administración del poder soberano, estoy a punto de creer que mi trabajo es tan inútil como el de La república de Platón. Porque también él es de la opinión de que es imposible superar los desórdenes del estado y el cambio de gobiernos mediante la guerra civil, hasta que los soberanos sean filósofos. Pero cuando considero nuevamente que la ciencia de la justicia natural es la única ciencia necesaria para los soberanos y sus principales ministros $[\ldots]$ recobro alguna esperanza de que, en un tiempo o en otro, este escrito mío caiga en las manos de un soberano que quiera considerarlo por sí mismo, sin ayuda de ningún intérprete interesado o envidioso, y que por el ejercicio de su soberanía entera al proteger su enseñanza pública, convierta esta verdad de especulación en utilidad de la práctica. (Hobbes 1994, pp. 243-244)

Lo que hace falta, pues, para que los estados alcancen cabal estabilidad y seguridad es sencillamente que sus gobernantes y sus gobernados sean educados para que entiendan y asimilen la ciencia de la justicia natural desarrollada por Hobbes. De esta forma, al comprender que el mal supremo es la muerte violenta y prematura, comprenderán la necesidad de acatar plenamente las leyes de la naturaleza y, aguijoneados por el miedo (tanto a sus semejantes como a la fuerza del poder soberano), se guiarán en su conducta práctica por esas leyes. Sabrán los súbditos, en otras palabras, que obedecer al soberano es, en el peor de los casos, un mal menor frente al 
mal mayor de la guerra de todos contra todos; y sabrán los gobernantes que siendo racionales podrán asegurar la permanencia de su poder soberano.

Lo anterior presupone al parecer dos cosas: la primera es que el miedo será siempre la pasión más poderosa, pues sólo así se sostendrá el impulso pasional capaz de contener a los otros impulsos pasionales. La segunda es que, en virtud de ese miedo, la razón expresada en las leyes de la naturaleza adquiere la fuerza para obligar en el foro externo, esto es, para superar o por lo menos contener las fuerzas irracionales de la superstición, el fanatismo y los errores promovidos por las doctrinas sediciosas.

\section{III}

La comparación entre la filosofía de Hobbes y la de Spinoza pone en evidencia, por un lado, un aire de familia común, relacionado con motivaciones e inspiraciones semejantes (por ejemplo, sustituir la vieja metafísica aristotélica tomista por una ontología y una antropología compatibles con los descubrimientos de la nueva ciencia inaugurada por Galileo), pero también, por otro lado, profundas diferencias en la forma de entender las exigencias y los resultados de la filosofía misma (para Hobbes, ésta no es sino una ciencia, un saber instrumental que debe servir, sobre todo, para alcanzar confort y para evitar los conflictos; para Spinoza, la filosofía es, antes que otra cosa, un proyecto ético, una manera de acceder a una vida superior). En este trabajo no nos interesa sino el contraste relativo al modo en que cada uno de estos autores se plantea la cuestión de la obligación política, de su origen y de su fundamento.

Como es sabido, Spinoza recupera en sus tres obras fundamentales -el Tratado teológico político, la Ética y el Tratado político- el vocabulario teórico iusnaturalista propuesto por Hobbes. Habla, por ende, de derecho natural, de leyes naturales y del pacto como origen del poder soberano (aunque de este último sólo alusivamente en el Tratado político). De ahí que algunos intérpretes hayan visto en las teorías políticas spinozistas una continuación y tal vez una corrección de los planteamientos hobbesianos. No obstante, el propio Spinoza, en una carta, apunta sus diferencias de fondo con Hobbes, y además remarca en su última obra su admiración por Maquiavelo. En este sentido, su apropiación del vocabulario iusnaturalista no basta para declararlo seguidor de Hobbes, pues este vocabulario sufre una clara redefinición que supone, como veremos, una mutación radical de la problemática de la obligación política.

Para empezar, la idea de derecho natural, que en el autor del Leviatán tenía un claro sentido normativo, jurídico-moral, en Spinoza es definida en términos de la potencia efectiva que caracteriza a cualquier individuo, humano o inhumano. En este sentido, toda cosa natural tiene tanto derecho 
como potencia, o, en otras palabras, tiene derecho a todo lo que puede. Dentro de la metafísica spinozista, entonces, por naturaleza todo lo que existe, incluidos los seres humanos, actúa en función de ciertas leyes naturales fijas que explican su comportamiento como expresión de su potencia relativa. El pez grande tiene derecho a comerse al chico porque lo puede hacer y porque está determinado a hacerlo, lo mismo que los seres humanos tienen derecho a hacer lo que hacen porque lo pueden hacer y están determinados a hacerlo. Lo único que "prohíbe", en este sentido, ese derecho natural es lo imposible: por ejemplo, "prohíbe" a los hombres volar como pájaros, de la misma manera que "prohíbe" a estos últimos dedicarse a la filosofía.

Por eso Spinoza insiste en que el derecho natural de los individuos humanos no se define por la razón, sino por la condición humana común, lo que significa que el derecho natural no es una idea acerca de lo que es racional y, por ende, debido; no sirve para interpelar a los seres humanos indicándoles lo que les está racionalmente permitido, sino, paradójicamente, es un modo de expresar que todo lo que hacen los hombres expresa su potencia relativa y por ende es natural. Así, mientras que en Hobbes la afirmación de que, en el estado de naturaleza, tenemos derecho a todo quiere decir que, siendo ésa una situación de guerra de todos contra todos, nos está permitido hacer todo aquello que creamos conducente para evitar la muerte, y que, por lo tanto, no tenemos ninguna obligación hacia nuestros semejantes-enemigos, en el caso de Spinoza la afirmación de que por naturaleza tenemos derecho a todo cuanto podemos significa simplemente que, como cualquier modo finito, tenemos un grado de potencia que explica nuestra conducta, lo cual permite entender por qué ese derecho natural se mantiene aun dentro del estado de sociedad civil, pues tanto en este último como en el estado de naturaleza siempre haremos todo aquello que podemos; esto es, siempre actuaremos de acuerdo con las leyes naturales propias de nuestra peculiar composición corporal y mental.

Ahora bien, Spinoza reconoce, como Hobbes, que por naturaleza los seres humanos son enemigos entre sí, es decir, entran necesariamente en conflicto. Pero, al mismo tiempo, a diferencia de Hobbes (y de Rousseau), postula que también por naturaleza requieren de los demás. Esta insociable sociabilidad de los seres humanos no se deriva, sin embargo, de un afán insaciable de poder, de una racionalidad "instrumental" que los conduzca a anticipar peligros y a buscar someter y utilizar a los demás, sino de la naturaleza peculiar de los afectos-pasiones humanos, de un conatus o deseo de perseverar en su ser que los define al mismo tiempo como necesariamente sociables (porque ese deseo se define por los deseos de los demás) y como necesariamente conflictivos (porque esa definición del deseo implica indefectiblemente un ingrediente egocéntrico, ilusorio, que expresa 
la impotencia y, en consecuencia, las tristezas y odios generados por los demás). No es posible entrar aquí en el detalle de esta dinámica pasional que explica precisamente por qué los seres humanos requieren un poder común coactivo para coexistir y colaborar socialmente. Más bien interesa señalar el papel teórico del pacto como origen de ese poder. En el Tratado teológico político, Spinoza propone la siguiente versión del tema:

para vivir seguros y lo mejor posible, los hombres tuvieron que unir sus esfuerzos. Hicieron, pues, que el derecho a todas las cosas, que cada uno tenía por naturaleza, lo poseyeran todos colectivamente y que en adelante ya no estuviera determinado según la fuerza y el apetito de cada individuo, sino según la potencia y la voluntad de todos a la vez. [... ] Por eso debieron establecer, con la máxima firmeza y mediante un pacto, dirigirlo todo por el solo dictamen de la razón (al que nadie se atreve a oponerse abiertamente por no ser tenido por loco) y frenar el apetito en cuanto aconseje algo en perjuicio de otro, no hacer a nadie lo que no se quiere que le hagan a uno, y defender, finalmente, el derecho ajeno como el suyo propio. (Spinoza 1986a, p. 335)

Como se ve, en este pasaje Spinoza sigue muy de cerca los planteamientos de Hobbes. No sólo habla de un pacto constitutivo del poder común, sino afirma que a través de ese pacto los hombres se comprometen "a dirigirlo todo por el solo dictamen de la razón", formulando como núcleo de dicho dictamen la misma regla de oro propuesta por el filósofo inglés: "no hacer a nadie lo que no se quiere que le hagan a uno". Sólo parece estar ausente la mención de las leyes de la naturaleza hobbesianas.

No se trata, sin embargo, de una ausencia inocente. A continuación, para explicar "cómo se debe llevar a cabo ese pacto para que sea válido y firme", Spinoza recurre a una "ley universal de la naturaleza humana" que ocupa su lugar otorgándole a la idea de pacto un sentido muy diferente: "que cada uno elegirá entre dos bienes el que le parece mayor, y entre dos males el que le parece menor. Digo expresamente: aquello que le parece mayor o menor al que elige, no que las cosas sean necesariamente tal como él las juzga." Ciertamente, Hobbes mismo, en El ciudadano, reconoce esta ley, pero sólo para intentar demostrar que si los hombres son racionales, tendrán siempre la ruptura de lo pactado como un mal mayor pues supone transgredir la tercera ley de la naturaleza. En cambio, Spinoza reconoce que toda la fuerza vinculante del pacto dependerá del juicio subjetivo de los individuos, de lo que ellos crean que es, en cada caso, el mal mayor o el bien menor: "de esta ley se sigue necesariamente que nadie prometerá sin dolo ceder el derecho que tiene a todo, y que nadie será en absoluto fiel a sus promesas sino por el miedo a un mal mayor o por la esperanza de un bien mayor" (Spinoza 1986a, p. 336). La obligación de obediencia generada por el pacto no se funda, entonces, en un teorema racional, en una regla general sugerida 
o dictaminada por la razón, sino en la opinión de los pactantes acerca de si es benéfico o perjudicial mantenerla o suspenderla. La ley natural spinozista es una ley causal, no un imperativo moral o prudencial, como la ley de la naturaleza en Hobbes.

Precisando sus diferencias con el autor del Leviatán, Spinoza replantea el ejemplo dado por éste del ladrón secuestrador que nos fuerza a prometerle la entrega de determinados bienes:

como mi derecho natural sólo está determinado por mi potencia, es cierto que, si yo me puedo librar de este ladrón con engaños prometiéndole cuanto él desee, el derecho de naturaleza me permite hacerlo, es decir, pactar con dolo cuanto él quiera. O supongamos que yo he prometido sin fraude a alguien que no tomaría alimento alguno durante veinte días, y que después he visto que mi promesa es estúpida y que no puedo guardarla sin gravísimo daño para mí. Dado que estoy obligado (causalmente) por derecho natural a elegir de dos males el menor, tengo el máximo derecho a romper mi compromiso y a dar lo dicho por no dicho. Y esto me está permitido por el derecho natural tanto si al percibir que mi promesa fue equivocada me fundo en la razón cierta y verdadera, como en la apariencia de una opinión; porque tanto si mi percepción es verdadera como si es falsa, temeré el máximo mal y, por prescripción de la naturaleza, me esforzaré en evitarlo de cualquier forma. (Spinoza 1986a, p. 336)

La fuerza del pacto no depende, entonces, sino de la utilidad aparente o real que tenga para los propios pactantes a lo largo del tiempo: "Por tanto, es necio pedir a alguien que nos sea siempre fiel a su promesa si, al mismo tiempo, no se procura conseguir que al que rompa el pacto contraído se le siga de ahí más daño que utilidad. Esta doctrina debe aplicarse sobre todo en el momento de organizar un Estado" (Spinoza 1986a, p. 337). Por supuesto, sigue diciendo Spinoza, si los hombres pudieran guiarse por la sola razón, "no habría nadie que no detestara de plano el engaño" y "todos cumplirían con toda fidelidad y detalle los pactos y guardarían, por encima de todo, la fidelidad, supremo baluarte del Estado". Pero tal presupuesto está muy lejos de la realidad efectiva, pues los hombres más bien son arrastrados por la inconstancia de sus pasiones.

De ahí que aunque los hombres prometan, con indudables signos de sinceridad, y se comprometan a ser fieles a su palabra, nadie puede, sin embargo, estar seguro de la fidelidad de otro a menos que se añada otra cosa a su promesa; ya que, por derecho de naturaleza, todo el mundo puede actuar con fraude y nadie está obligado a observar los pactos si no es por la esperanza de un bien mayor o por el miedo de un mayor mal. (Spinoza 1986a, p. 337)

Bajo estas premisas, la idea de un pacto constitutivo del poder soberano, de una transferencia del derecho natural de los individuos como origen de 
su obligación de obedecer, adquiere un significado muy diferente del que tenía en las obras de Hobbes. Por una parte, el motivo real de la obediencia no es tanto el pacto o las promesas por sí mismas, sino la creencia subjetiva, siempre contingente, de que el respetar ese pacto o cumplir esas promesas supone un bien mayor o un mal menor. Lo que implica que no la razón, sino la esperanza y el miedo serán, en cuanto pasiones políticas, el fundamento o, por decirlo mejor, la causa de esa obediencia y, por ende, de ese poder soberano.

Por consiguiente tendrá el supremo derecho sobre todos quien posea el poder supremo con el que puede obligarlos a todos por la fuerza o contenerlos por el miedo al supremo suplicio, que todos temen sin excepción. Y sólo mantendrá ese derecho en tanto en cuanto conserve ese poder de hacer lo que quiera; de lo contrario mandará en precario y ninguno que sea más fuerte estará obligado a obedecerlo si no quiere. (Spinoza 1986a, p. 338)

Si lo que Hobbes pretende demostrar es que debemos obedecer al soberano porque, siendo racionales, sólo nos queda someternos para lograr la paz y evitar la muerte violenta y prematura, en cambio, lo que Spinoza propone es que el soberano es tal sólo en la medida en que logra infundir el miedo y la esperanza que motivan (causalmente) la obediencia. Mientras la primera teoría remite, entonces, al fundamento racional de la obligación política, de su legitimidad sustentada en las leyes de la naturaleza, y por consecuencia a una demostración presuntamente apodíctica que, mediante la educación, convertiría en racionales a los hombres, lo que permitiría superar teóricamente toda disensión o enfermedad intestina de los Estados, la segunda refiere al problema práctico organizativo de los recursos que los que detentan el poder soberano han de emplear para mantener las pasiones y opiniones que justifican, para los propios súbditos, el mantener su sumisión; esto es, que legitiman en los hechos ese poder. Por eso Spinoza reconoce que se trata de una tarea no filosófica (pues la filosofía apenas puede impactar a los pocos que la asumen como una forma de vida y un proyecto ético) sino política, en la que las religiones y sus recursos imaginativo-pasionales desempeñan un papel crucial motivando miedos y esperanzas colectivas.

Por otro lado, mientras que Hobbes pretende demostrar la naturaleza casi incondicional de la obediencia y, por ende, el carácter absoluto del poder soberano, por cuanto sólo así es posible racionalmente evitar sediciones y guerras civiles, Spinoza, en cambio, reconocerá que la supuesta transferencia del derecho natural y, por ende, la obediencia de los súbditos al poder siempre implicarán determinados límites fácticos:

Nadie podrá jamás transferir a otro su poder ni, por tanto, su derecho, hasta el punto de dejar de ser hombre; ni existirá jamás una potestad suprema que 
pueda hacerlo todo tal como quiera. En vano mandaría a un súbdito que odiara a quien le hizo un favor y amara a quien le hizo daño, que no se ofendiera con las injurias, que no deseara liberarse del miedo y muchísimas otras cosas que se derivan necesariamente de las leyes de la naturaleza humana. Pues nunca los hombres cedieron su derecho ni transfirieron a otro su poder, hasta el extremo de no ser temidos por los mismos que recibieron su derecho y su poder, y de no estar más amenazado el Estado por los ciudadanos, aunque privados de su derecho, que por los enemigos. (Spinoza 1986a, pp. 350-351)

También, entonces, el derecho de las supremas potestades está determinado por su potencia, por lo que pueden. Y, en los hechos, no pueden convertir a los seres humanos en autómatas, en meros instrumentos de su voluntad, pues éstos mantendrán siempre su derecho-potencia de juzgar y, por ende, de decidir si deben o no obedecer. De ahí que el sueño de los tiranos, de alguna manera racionalizado por Hobbes, de lograr obediencia incondicional sobre la base del miedo, de las solas amenazas de coacción o del peligro de la guerra civil, sea, para Spinoza, políticamente contraproducente. Pues siendo una pasión poderosa y políticamente indispensable, el miedo es una "tristeza inconstante surgida la imaginación de una cosa dudosa" que disminuye nuestra potencia mental y corporal y que, por consecuencia, se opone al conatus constitutivo de la naturaleza humana que, por el contrario, "se esfuerza en imaginar las cosas que aumentan o favorecen la potencia de obrar del cuerpo" (Spinoza 1987, pp. 188, 193). Por eso, el miedo genera odio; el odio, indignación, y la indignación, rebelión.

[H]ay que señalar que la potestad del Estado no consiste exclusivamente en que puede forzar a los hombres por el miedo, sino en todos aquellos recursos con los que puede lograr que los hombres acaten sus órdenes. Porque lo que hace al súbdito no es el motivo de la obediencia, sino la obediencia misma. Cualquiera que sea, en efecto, el motivo por el que un hombre se decide a cumplir las órdenes de la suprema potestad, ya sea porque teme el castigo, o porque espera conseguir algo, o porque ama a la patria, o porque lo impulsa cualquier otro sentimiento, decide según su propio juicio, y sin embargo, obra por mandato de la suprema potestad. (Spinoza 1986a, p. 351)

Como se ve, Spinoza rechaza tajantemente no sólo que el poder soberano se sustente en la razón o en las leyes de la naturaleza en el sentido hobbesiano. Rechaza también la prioridad del miedo como pasión motivadora en exclusiva de la obediencia, dado el carácter inconstante y sobre todo negativo de dicha pasión. Ello le permite distinguir claramente entre formas de organización del poder desviadas, tiránicas y opresivas, y formas rectas de organización del poder democráticas y libres, o lo que es lo mismo, entre pueblos esclavizados y pueblos libres. 
De los fundamentos del Estado se sigue que su fin último no es dominar a los hombres ni sujetarlos por el miedo y someterlos a otro, sino, por el contrario, liberarlos a todos del miedo para que vivan, en cuanto sea posible, con seguridad; esto es, para que conserven al máximo ese derecho suyo natural de existir y de obrar sin daño suyo ni ajeno. El fin del Estado, repito, no es convertir a los hombres de seres racionales en bestias o autómatas, sino lograr más bien que su mente y su cuerpo desempeñen sus funciones con seguridad [...]. El verdadero fin del Estado es, pues, la libertad. (Spinoza 1986a, pp. 410-411)

Resta, sin embargo, un problema. Si en Hobbes el poder se origina en y con el pacto de sumisión, en Spinoza ese pacto, para ser firme y válido, requiere "que se añada otra cosa". Esa otra cosa sólo puede ser la capacidad de generar y sostener la creencia de los súbditos de que la obediencia o es un mal menor o es un bien mayor, es decir, paradójicamente, el poder mismo. ¿Pero cómo surge o de dónde sale ese poder? En las páginas del Tratado teológico político no existe una respuesta precisa para este problema. Todo ocurre ahí como si la ficción teórica del pacto, aun reformulada en los términos que hemos visto, impidiera un planteamiento adecuado del problema del fundamento no normativo sino fáctico del poder. Se entiende, entonces, que sólo en el Tratado político, que justamente prescinde de la hipótesis contractualista, Spinoza lo afronte de la siguiente forma:

Tiene a otro bajo su potestad, quien lo tiene preso o quien le quitó las armas y los medios de defenderse o de escaparse, o quien le infundió miedo o lo vinculó a él mediante favores, de tal suerte que prefiere complacerle a él más que a sí mismo y vivir según su criterio más que según el suyo propio. Quien tiene a otro bajo su potestad de la primera o la segunda forma, sólo posee su cuerpo, pero no su mente; en cambio quien lo tiene de la tercera o la cuarta forma, ha hecho suyos tanto la mente como su cuerpo, aunque sólo mientras persista el miedo o la esperanza, pues, tan pronto desaparezca ésta o aquél, el otro sigue siendo autónomo. (Spinoza 1986b, p. 90)

La potestad, el poder como dominio de unos seres humanos sobre otros, puede basarse en la fuerza física, pero entonces se trata de un poder precario que sólo somete el cuerpo pero no la mente, o bien puede sustentarse en la capacidad de presentarse como causa de miedos y esperanzas que afectan la mente y, por ende, también el cuerpo, lo que la convierte en un poder más completo y eficaz, pero sólo "mientras persista el miedo y la esperanza". En este sentido, la hipótesis contractualista no puede explicar en modo alguno el origen de la potestad o del dominio, pues: 
La promesa hecha a alguien, por la que uno se comprometió sólo de palabra a hacer esto o aquello que, con todo derecho, podía omitir o al revés, sólo mantiene su valor mientras no cambie la voluntad de quien hizo la promesa. Pues quien tiene la potestad de romper la promesa, no ha cedido realmente su derecho, sino que sólo ha dado su palabra. (Spinoza 1986b, p. 91)

Por consiguiente, no son las promesas ni los pactos los que dan origen a la potestad como dominio. Se hace necesario apelar a otra fuente de la capacidad para generar miedos y esperanzas que permitan esa potestad o dominio. Al respecto dice Spinoza: "Si dos se ponen de acuerdo y unen sus fuerzas, tienen más poder juntos y, por tanto, más derecho sobre la naturaleza que cada uno por sí solo. Y cuantos más sean los que ponen sus fuerzas en común, más derecho tendrán todos unidos" (Spinoza 1986b, p. 92). Es la unión, el acuerdo, la coordinación de esfuerzos lo que entonces genera una potencia superior capaz de generar miedos y esperanzas colectivas y capaz, por consiguiente, de motivar la obediencia de unos hacia otros. "Allí donde los hombres poseen derechos comunes y todos son guiados como por una sola mente, es cierto que cada uno de ellos posee menos derecho cuanto los demás juntos son más poderosos que él; es decir, que ese tal no posee realmente sobre la naturaleza ningún derecho, fuera del que le otorga el derecho común" (Spinoza 1986b, p. 93).

No es, como quería Hobbes, la sumisión la que hace posible la unión, sino al revés, la unión la que posibilita la sumisión, pues el derecho de la potestad soberana, su capacidad para hacerse obedecer, "se define por la potencia de la multitud". Por razones históricas, por la barbarie e ignorancia de las multitudes, esa unión puede exigir de reyes o caudillos guerreros que parezcan por sí solos la causa de los miedos y las esperanzas colectivas y que, por consiguiente, concentren en sus personas individuales la potestad y el dominio. De ahí su pretensión de encarnar fuerzas sobrenaturales, de presentarse como dotados de cualidades extraordinarias y de utilizar los miedos y esperanzas teológicas para justificar su poder. Pero, por eficaces que puedan ser en ciertas condiciones tales recursos, no dejan de sustentarse en una ilusión.

No cabe duda que quienes creen que es posible que uno solo detente el derecho supremo de la sociedad, están muy equivocados. Pues el derecho se mide por la sola potencia y la potencia de un solo hombre es incapaz de soportar tal carga. De ahí que el rey, que la multitud eligió, se rodee de jefes militares, consejeros o amigos, a los que confía la salvación propia y de la comunidad. Y así, el Estado (imperium) que pasa por ser una monarquía absoluta es, en la práctica, una verdadera aristocracia, no manifiesta sino latente, y por eso mismo, pésima. (Spinoza 1986b, p. 124) 
El origen del poder político y su fundamento no están en un pacto de transferencia de derechos, en una renuncia de éstos a favor de una persona o de una asamblea, sino en la unión y organización institucional de una multitud que, bajo diversas formas, se guía como por una sola mente; esto es, se (auto)gobierna generando instancias encargadas de tomar decisiones y establecer leyes válidas para toda la sociedad. De donde deriva la preferencia de Spinoza por la democracia como forma más absoluta de organizar el poder (en la medida en que reduce al mínimo la escisión entre gobernantes y gobernados), lo mismo que sus propuestas para "democratizar" al máximo las monarquías y las aristocracias.

En suma, para Spinoza la obligación política no puede fundarse racionalmente, pues tal proyecto presupone una racionalidad que, si existiera, haría inútil la propia necesidad de la obligación política. En otras palabras, si los hombres pudieran guiarse por la razón, no habría necesidad alguna de la política y sus recursos (la fuerza, las ideologías), pues los hombres concordarían entonces espontáneamente. Siendo enteramente racionales, no requerirían ni ser obligados (coactivamente) ni tener obligaciones (moralmente). Esto es lo que parece tener en mente cuando afirma que los filósofos no han "ideado jamás una política que pueda llevarse a la práctica, sino otra que o debiera considerarse una quimera o sólo podría ser instaurada en el país de la Utopía o en el siglo dorado de los poetas, es decir, allí donde no haría falta alguna" (Spinoza 1986b, p. 78).

La piedad, el sentimiento del deber, no se fundan en la razón sino en la imaginación, en lo que Spinoza llama en el Tratado teológico político "la certidumbre moral", que nos lleva a pensar que nuestra salvación o salud espiritual depende de obedecer libremente determinadas reglas, sea como mandamientos, sea como imperativos prudenciales, sea (en el caso más raro) como normas generales ligadas a un proyecto ético individual. De ahí que la filosofía pueda, en todo caso, entender causalmente la política, y a partir de ello, coadyuvar a sugerir medidas políticas orientadas a buscar una mejor eficacia de sus ordenamientos institucionales; pero que no pueda, en cambio, sustituirla.

\section{IV}

A partir de lo anterior sería conveniente volver a nuestro punto de partida, es decir, a los planteamientos de Rousseau. Por razones de espacio sólo es posible indicar que los argumentos del filósofo ginebrino se ubican en un contexto teórico "poscosmológico", en la medida en que ya no parte de una concepción determinista sobre la naturaleza, sino de un análisis casi lingüístico sobre el significado de tener una obligación, un deber, un derecho, y sobre los presupuestos de tal significado. De ahí que a Rous- 
seau no le interese ya el ser humano "tal como es", sino en cuanto "agente moral racional". Que no se preocupe, por ende, por las formas efectivas de legitimación, sino por un razonamiento práctico normativo acerca de lo que puede otorgar legitimidad a nuestras cadenas. Pero estos problemas tendrían que desarrollarse en otro artículo.

\section{BIBLIOGRAFÍA}

Barry, B., 1968, "Warrender and His Critics", en King 1993.

Hobbes, Th., 1994, Leviathan, ed. Edwin Curley, con variantes seleccionadas de la edición latina de 1688, Hackett, Indianápolis.

—_, 1993, El ciudadano, ed. Joaquín Rodríguez Feo, Csic/Debate, Madrid.

Kavka, G., 1986, Hobbesian Moral and Political Theory, Princeton University Press, Nueva Jersey.

King, Preston (comp.), 1993, Critical Assessments, Routledge, Londres.

Moore, S., 1972, "Hobbes on Obligation, Moral and Political. Part Two: Political Obligation", en King 1993.

_, 1971 , "Hobbes on Obligation, Moral and Political. Part One: Moral Obligation", en King 1993.

Nagel, T., 1959, “Hobbes's Concept of Obligation”, en King 1993.

Rousseau, J.-J., 1977, Du contrat social, Seuil, París.

Salazar, L., 1998, El síndrome de Platón: ¿ ¿Hobbes o Spinoza?, Universidad Autónoma Metropolitana, México.

Spinoza, B., 1987, Ética, Alianza, Madrid.

——, 1986a, Tratado teológico político, trad., introd. y notas de Atilano Domínguez, Alianza, Madrid.

—_, 1986b, Tratado político, Alianza, Madrid.

Taylor, A.E., 1938, “The Ethical Doctrine of Hobbes", en King 1993.

Warrender, H., 1962a, "Hobbes's Conception of Morality”, en King 1993.

__, 1962b, "Obligations and Rights in Hobbes", en King 1993. 